\title{
Recoveries of function after brain damage: Variables influencing retrieval of latent memories
}

\author{
T. E. LeVERE \\ North Carolina State University, Raleigh, North Carolina
}

When I was asked to participate in a symposium concerned with long-term memory, my reaction was: why? I am a physiological psychologist interested in recovery of function after brain injury and not a cognitive psychologist who would know about such matters. Then I remembered what caused my addiction to the question of recovery of function. It was a paper on memory presented to this organization some 13 years ago by Don Meyer. The paper was his presidential address, entitled "Access to Engrams" (D. R. Meyer, 1972), and in it Don reported that amphetamine would facilitate the postoperative recovery of a preoperatively learned brightness discrimination (Braun, P. M. Meyer, \& D. R. Meyer, 1966). By itself, this was not terribly addictive, because amphetamine does many things. However, the hook came when Don told us what amphetamine does not do. It does not similarly affect the original learning of a brightness discrimination in lesioned rats. Because the drug facilitated the recovery of what was previously learned but not the original learning of the same behavior, Don Meyer speculated that the behavioral dysfunctions that follow brain injury may be mnemonic in nature. Accordingly, the process of recovery was not relearning that which was lost, but rather remembering that which was spared.

An interesting proposition, if true, but one directly at odds with the prevailing wisdom so masterfully established by Lashley (1935). And more importantlywith all respect to Professor Lashley-if the proposition was true, then it would suggest that we shift the emphasis of our research questions from the process of recovery to the nature of the behavioral dysfunction. In other words, if a behavior is never gone, then how you reestablish its neural substrates is not the issue. Rather, the issue is why the behavior is not expressed. What I would like to do here is first convince you that Don Meyer's suggestion is, in fact, true. Then I would like to describe some of our research concerning why spared memories are difficult

The research was supported by Research Grant NS-12459 from the National Institute of Neurological and Communicative Disorders and Stroke. The author's mailing address is: Neuropsychology Laboratory, Department of Psychology, Box 7801, North Carolina State University, Raleigh, NC 27695-7801. to retrieve after neocortical injury. In this regard, there are two central issues. On the one hand, does brain injury change the fundamental nature of spared memories so that they are harder to retrieve or, on the other hand, do the memories remain unchanged and the injury affect the way we operate on these memories? A question of structure versus function, if you like? We initially thought the former was correct, but now believe that we were wrong and that the latter is nearer the truth.

\section{A Behavioral Replication}

The year following Meyer's presentation, Jerry Morlock (T. E. LeVere \& Morlock, 1973) directly tested the proposition that the memories of a preoperatively learned visual behavior are not destroyed by visual decortication. This is a rather old experiment, and I mention it only because it forms the basis of what follows. In general, the experimental design was a proactive interference paradigm in which normal rats were trained on a brightness discrimination, subjected to visual decortication, and then retrained on the preoperative habit or the reversal of the preoperative habit. We had two predictions. If Lashley was correct and visual decortication destroyed the memory engrams of the preoperative behavior, then postoperative recovery would necessarily be a relearning process and both groups should perform the same. On the other hand, if Meyer was correct and the memories of the preoperative habit survived visual decortication, then recovery could be a process of remembering. If this were the case, then the nonreversal group should be quite impaired, inasmuch as these animals would remember just the opposite of what they had to do. The two sets of bars on the left of Figure 1 present the data and show that there is a significant impairment associated with postoperative reversal training; the scores on this issue: Ohio State, 1 ; Orange Park, 0 . Moreover, because there was some concern that brightness preferences in normal and lesioned rats might have influenced these data, Morlock (T. E. LeVere \& Morlock, 1974) replicated the procedure using a successive brightness paradigm in which this could not be an issue. The results are given on the right of Figure 1, where they even more dramatically demonstrate the postopera- 


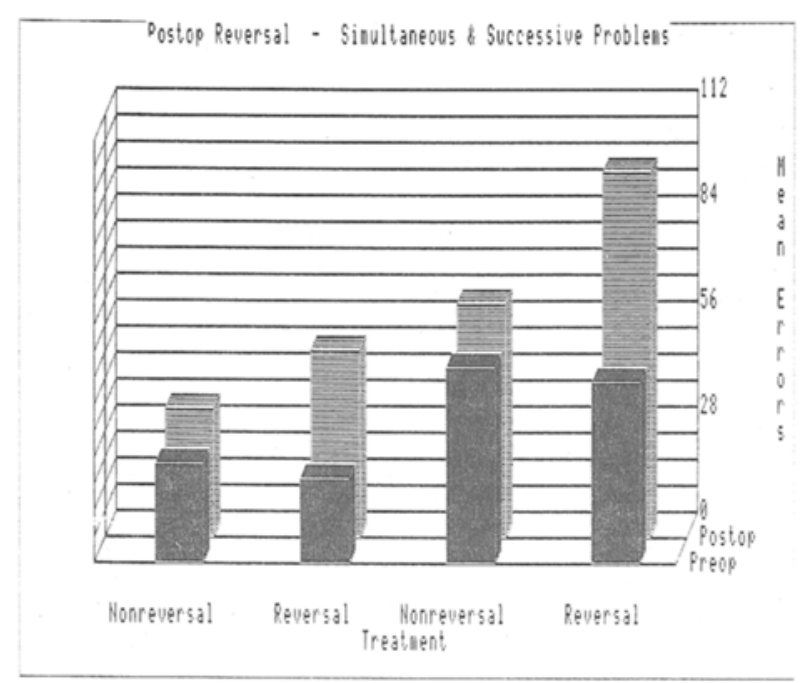

Figure 1. Mean errors to criterion for preoperative (front bars) and postoperative (rear bars) training when animals postoperatively recover a nonreversal or a reversal of the preoperative brightness habit. The left two pairs of bars are for a simultaneous discrimination problem, and the right two pairs of bars are for $a$ successive discrimination problem.

tive reversal deficit. Apparently, whatever the visual decorticate rat's handicap is, it is not a loss of memory.

\section{More Sparing}

As it turns out, the lesioned rat's postoperative behavior is quite misleading and much of what is learned preoperatively survives visual decortication. For example, it is not only the memory of what was correct that is spared, but also the memory of what motivated the animal to establish the memory. The data relative to this was collected by Linda Gonder (T. E. LeVere, Davis, \& Gonder, 1979), and the experimental strategy was conceptually the same as that employed by Morlock (T. E. LeVere \& Morlock, 1973). That is, would what was learned preoperatively survive neocortical injury and influence postoperative behavior? In this case, however, the question centered on motivation, and Gonder elected a direct approach. Initially, she trained three groups of normal rats on a brightness discrimination to avoid/escape pulsating footshock set at an intensity of $0.3,0.5$, or $0.8 \mathrm{~mA}$. After learning the discrimination, all the animals sustained visual decortication, were allowed a 2-week rest, and then were tested for retention of the preoperative behavior. Although all three groups preoperatively learned the discrimination with equal efficiency, each averaging about 20 errors, Figure 2 shows that the groups did not experience the same amount of shock. The $0.3-\mathrm{mA}$ group received a significantly greater number of shocks than either the 0.5 or 0.8 animals, which were not statistically different. The postoperative retention test after recovery from surgery was a 1-day affair involving 10 trials, in which the animal was simply placed in the startbox of the apparatus and left there for a maximum of 2 min without being shocked. We had two questions. First, would the rat remember the preoperative motivation and run to the goal areas? Second, and more importantly, would there be a difference between the groups that could be related to their preoperative experience? Regarding the first question, all animals ran to the goal area on some of the retention test trials, averaging $10 / 10,7 / 10$, and $6 / 10$ trials, respectively, for the 0.3-, 0.5-, and 0.8-mA groups. Although these differences did not distinguish between the groups, the average response latency did, as shown in Figure 3. Here it can be seen that the 0.3$\mathrm{mA}$ group, that is, the preoperative group that received the greatest number of shocks, responded significantly faster than either of the other two groups. Apparently, the memory of the preoperative motivation was intact, retrievable, and quite able to influence the lesioned rat's postoperative behavior. Unfortunately, even though the animals were able to retrieve the memory of the preoperative shock motivation, this was not the case for the memory of the visual discrimination, and all responded at chance with respect to the brightness cues.

\section{The Importance of Motivation}

Since the lesioned rats remembered that they had to do something but could not recall exactly what it was, it seemed to us that the memory of the motivational state was quite potent and might be a key to the retrieval of other memories following brain injury. Accordingly, Nancy Davis (LeVere \& Davis, 1977) ran two replications of the Morlock (T. E. LeVere \& Morlock, 1973) reversal procedure. The

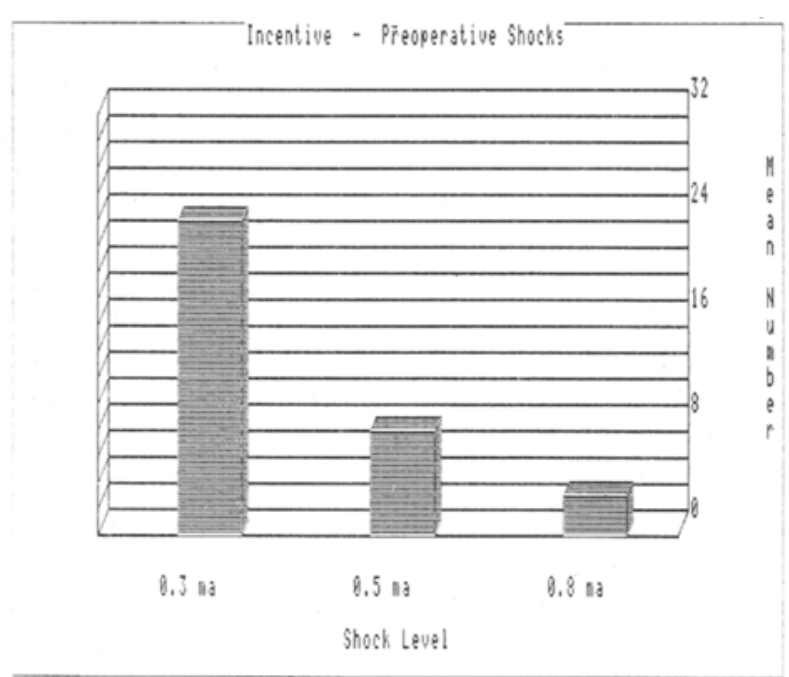

Figure 2. Number of preoperative shocks received while attaining criterion performance when the shock intensity was $0.3,0.5$, or $0.8 \mathrm{~mA}$. 


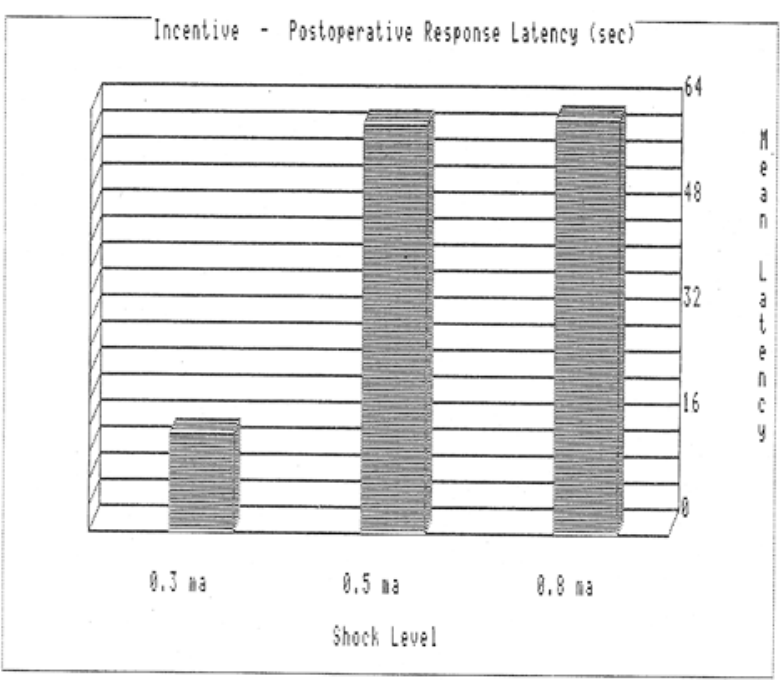

Figure 3. Postoperative response latency for animals preoperatively trained with $0.3-, 0.5-$, or $0.8-\mathrm{mA}$ shocks.

first was a direct replication, except that the animals were trained for water reward. The second replication used water for preoperative original learning but shock motivation during recovery training. Our question in this latter experiment was, of course, whether changing the animal's motivational state would influence the retrieval of spared preoperative memoriesthat is, would there be less of a reversal impairment. The results of the first experiment are shown in Figure 4. Again, there is a rather significant reversal impairment, as Morlock found, so motivation is not critical to what is spared. However, as shown in Figure 5, what motivates the animal is quite critical to what is retrieved. Specifically, the reversal impairment vanishes if the animal is postoperatively trained under a different motivational state. This result somewhat surprised us, for two reasons. First, Davis's initial experiment showed that the memory of the waterrewarded habit was spared. Second, it is a trivial matter to show that memories are retrievable under different motivational states if all training is either pre- or postoperative. Apparently, we thought, brain injury somehow changed memories and made them quite specific so that retrieval required duplication of the conditions under which the memories were established.

\section{The Specificity-Transfer Hypothesis}

Suggesting that spared memories are specific, however, is not very satisfying. The important concern is to understand the nature of this specificity, and for an initial go at it we turned to the classic transferof-training analysis of Osgood (1949). Our thought was that brain injury might induce a "perceptual" change in spared memories so that, following visual decortication, the lesioned animal would be further out on Osgood's surface. We also thought that changes in motivation could be similarly interpreted. If the consequences of a visual lesion and a change in motivation were additive, then their combined effects might yield a situation so dissimilar that memory retrieval should not be expected. Or, from the animal's point of view, it was not a question of what memories could be retrieved but, rather, what memories were applicable. In fact, the mean errors associated with different conditions of reversal training shown in Figure 6 lend some support to this inter-

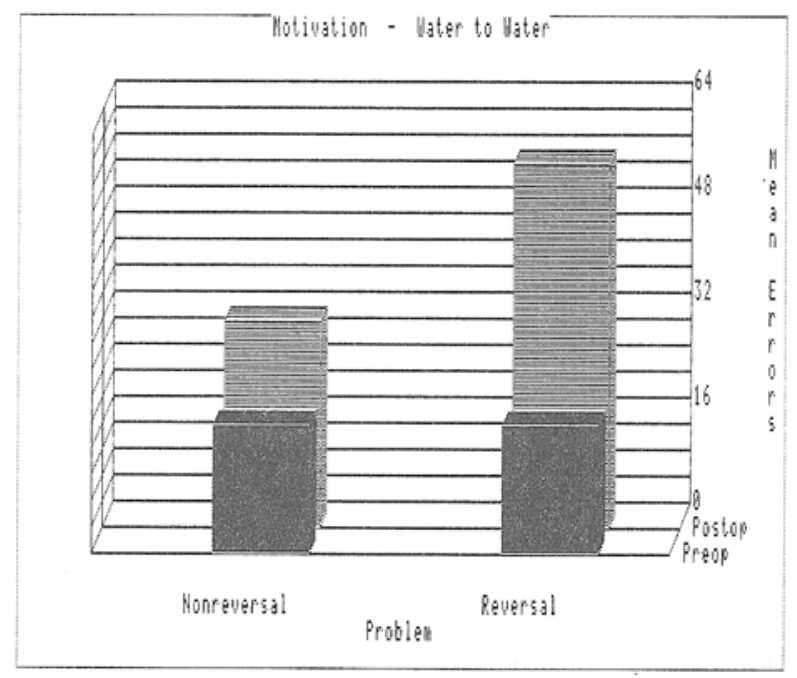

Figure 4. Mean errors to criterion for preoperative (front bars) and postoperative (rear bars) training when animals postoperatively recovered a nonreversal or a reversal of the preoperative brightness habit. Both preoperative training and postoperative recovery were water rewarded.

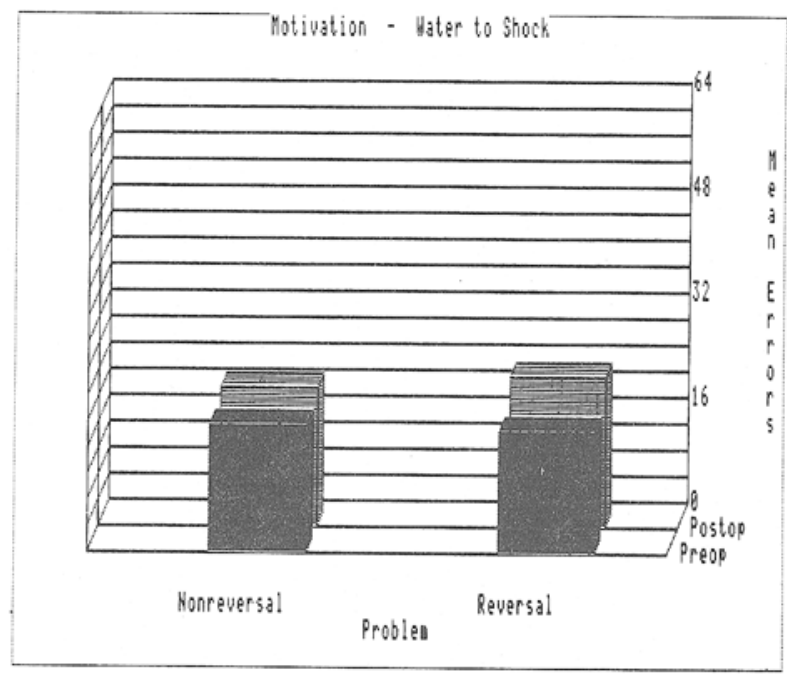

Figure 5. Same as Figure 4, except that the animals were preoperatively trained for water reward and postoperatively recovered the brightness discrimination to avold/escape footshock. 


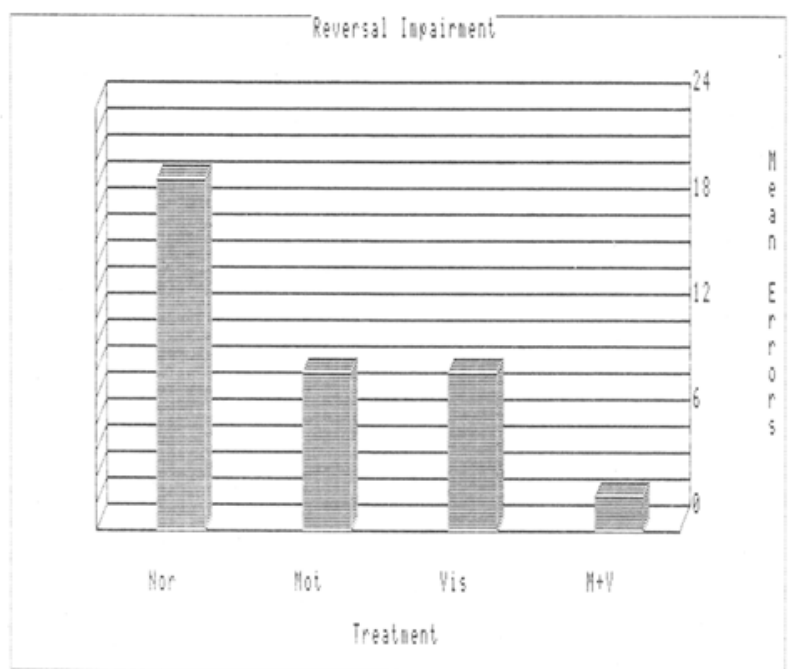

Figure 6. The mean number of errors committed when normal rats are trained on a reversal problem (Nor), when normal animals are trained on the reversul for a different motivation (Mot), when the animals sustain visual decortication before reversal training (Vis), and when there is both a change in motivation and a visual lesion before reversal training $(M+V)$.

pretation. On the far left, the data, estimated from the figures of Mackintosh, McGonigle, Holgate, and Vanderver (1968), show that normal rats will commit about 20 errors when learning the reversal of a previously acquired brightness discrimination. However, this reversal impairment drops to 9 errors when there is a motivational change between the initial learning and reversal training (T. E. LeVere \& Davis, 1977), as shown by the next bar. Again, the data are from normal animals. Similarly, there is a 9-error reversal impairment when a visual lesion intervenes between initial learning and reversal training (T. E. LeVere \& Morlock, 1973). In other words, a change in motivation in normal animals or a visual lesion will roughly halve the usual reversal impairmentand, we thought, for the same basic reason. In each case, the manipulation causes a perceptual change which decreases the similarity between the two training situations and leads to less proactive interference. Finally, as shown by the far right bar, if the rat must deal with both a change in motivation and visual decortication, then the situations become so dissimilar that the memories of the preoperative behavior become a "nonissue."

At the same time that we were enjoying this small bit of theoretical derring-do, parsimony being as rewarding as it is, we were also somewhat depressed. The problem was that it seemed that there was little that could be done to improve the retrieval of spared memories and facilitate recovery of function, since the changes induced by neocortical injury should be constant. However, while we appreciated the resilience of Osgood's surface and knew we could not hope to reshape it, we nonetheless felt that we might be able to dent it a bit (Davis \& T. E. LeVere, 1982). Our reasoning was that perhaps part of the memory change induced by visual decortication might occur because the striate lesioned animal did not fully utilize visual information. If this was the case, then it should be possible to improve retrieval of spared memories by first establishing the viability of the lesioned rat's visual system.

Our procedure (Davis \& T. E. LeVere, 1982) to test this was the standard train-lesion-retrain paradigm, using a two-choice brightness discrimination problem. However, before the lesioned animals were retrained on the preoperative discrimination, one-third of them were required to master a successive brightness discrimination in a two-bar operant chamber. This situation was such that when the wall of the operant chamber was illuminated, a VI schedule for food reward was in effect for the left bar, and when the wall of the chamber was dark, the VI schedule was in effect for the right bar. The remaining animals were divided into two yoked groups. One of these experienced the operant chamber but under conditions in which the visual cues were unrelated to which bar was being reinforced. The third group simply remained in their home cages. As each animal in the successive discrimination group reached criterion, it and its two yoked partners were returned to our Yerkes box and retrained on the preoperatively learned simultaneous discrimination. The results of this training are given in Figure 7; while the trend of the data is in the predicted direction, the absolute range of

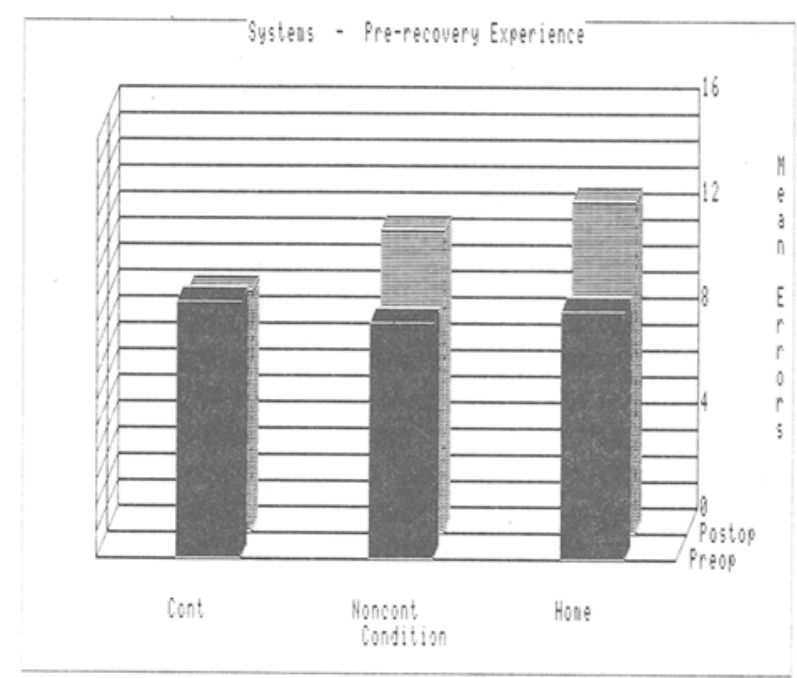

Figure 7. Mean errors to criterion for preoperative (front bars) and postoperative (rear bars) training. "Cont" refers to animals given successive brightness discrimination training in an operant chamber. "Noncont" refers to animals trained in the same operant chamber, but where the brightness cues were noncontingent with the reinforced bar. "Home" refers to animals that remained in their home cages during the same time. 
errors is only 4 and not statistically reliable. Thus, forcing the visual decorticate rat to use its visual system in some meaningful manner does not effectively restore the potency of spared visual memories. We could not dent Osgood's surface or even scratch it very deeply.

Yet the trend was in the right direction, and we were constantly reminded, by one of the present panel members, that amphetamine would facilitate recovery of function. In addition, our own research (Davis \& T. E. LeVere, 1979) suggested that spared memories were more available if postoperative learning was prevented with the RNA antimetabolite 8azaguanine. Clearly, the unavailability of spared memories could not be explained by suggesting that brain injury somehow changed memories and made them more specific-unless, of course, amphetamine and 8-azaguanine change them back, a proposal difdicult even for us to accept. But if not a change in memories, then what?

\section{An Alternative to the Specificity Explanation}

What I would like to suggest is that perhaps the answer was provided nearly two decades ago by Jim Sprague (1966). The research I am referring to is Sprague's nice demonstration that visual orienting deficits associated with unilateral visual decortication can be reversed by contralateral superior colliculus lesions. Sprague interpreted these data as indicating that the unilateral visual decortication initially produced an imbalance in the visual system due to the loss of cortical facilitation of the superior colliculus. The restoration of appropriate orienting behavior following contralateral superior colliculus ablation, then, was the result of "rebalancing the system" by removing the normal inhibitory influences of this structure. What we would like to suggest here is that this is not an intrasystem concept but, rather, a general principle, perhaps, that applies to the interaction between functional neural systems.

Returning to the problem of memory retrieval following visual decortication, we would like to suggest that when retrieval fails, it fails not because the visual lesion affects memories per se. Rather, we suggest that memories are not retrieved because the animal simply does not utilize the functional neural system with which the memories are associated. More particularly, it is now our position that localized neocortical injuries have widespread effects, which change the normal interaction, balance, between functional neural systems. The effect of this imbalance is to cause nonlesioned neural systems to dominate behavior, which, in turn, prevents the retrieval of spared memories associated with the lesioned neural system. While this position may be acceptable to clinical neurologists who enjoy Luria's $(1962 / 1980)$ analysis, it is probably somewhat strange to the academic neuroscientist. However, the proposition is testable and it is to this test that I would now like to turn.

The research I refer to was designed to determine whether visual decortication would predispose rats to preferentially utilize nonvisual cues. Our initial experiment in this series (T. E. LeVere \& N. D. LeVere, 1982) was an attempt to equate the saliency of a pair of nonvisual cues with the visual cues we typically use in our research. To do this, we trained normal rats with a number of different compound nonvisual/ visual cues and then tested for transfer to either the nonvisual component or the visual component. What finally worked were brightness cues with values of 64 and $1 \mathrm{fL}$ and an upright and inverted triangular stepthrough haptic cue. Figure 8 diagrams the general test situation and shows that the haptic cues were located in front of the doors to the goal areas, which provided the brightness cues. Thus, the rat had to crawl over or under a particular haptic cue before attempting to enter a goal area.

The paradigm we used with the normal rats is shown is shown in Figure 9. As can be seen, whenever the brightness cues were present, they were relevant, with the dim cue always signifying the correct door. However, the haptic cues could be either relevant (Hr), with the inverted triangle also signifying the correct choice, as illustrated at the top of the figure, or irrelevant $(\mathrm{Hi})$ and randomly paired over trials with the brightness cues, as shown at the bottom of figure. Also, as shown in the figure, half the animals initially trained with the brightness/haptic relevant compound $(\mathrm{B} / \mathrm{Hr})$ were subsequently tested for transfer with just brightness cues, and the remaining animals were tested for transfer with just haptic cues. The brightness/haptic irrelevant group was, of course, tested for transfer with only the brightness cues. The results of the initial training and transfer tests are also given in this figure, by the numbers above each cue condition which represent mean error scores to our usual $9 / 10$ criterion. I think it is obvious from these data, and particularly from the results of the transfer tests, that the normal rat's learning is about equally affected by both components of the compound brightness/haptic cue. Our question now was whether this would also be the case for the visual decorticate rat, and we predicted it would not.

The experimental design and results are shown in Figure 10, and the results, we believe, support this prediction. For example, when previously lesioned rats are initially trained on the $\mathrm{B} / \mathrm{Hr}$ compound, they average less than 4 errors to reach criterion performance-a score that is significantly better than what we found with the normal rats. However, when tested for transfer, these same animals commit almost 10 errors to reattain criterion performance with only the brightness cues. Clearly, the visual decorticate rat's superior performance was determined by the availability of, and its preference for, haptic infor- 


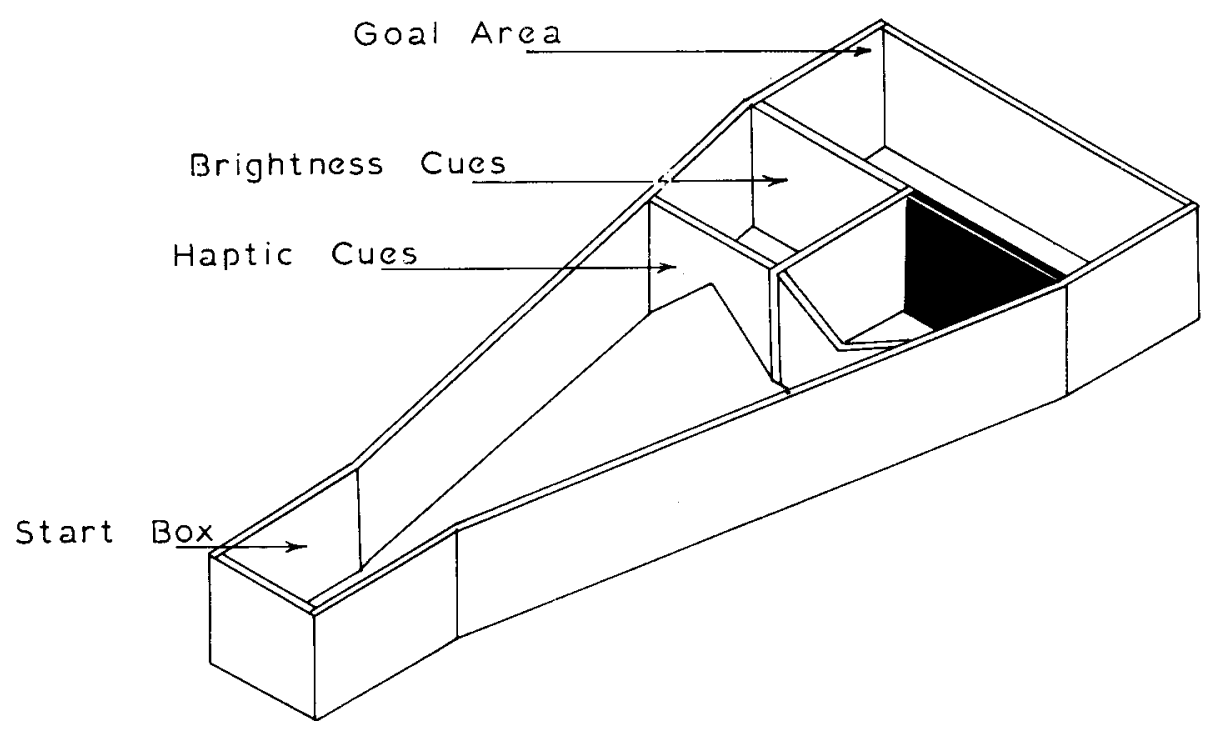

Figure 8. Line diagram of the apparatus constructed for compound-cue training.

mation. The increase in mean error score, almost double in the normal animals with regard to the $\mathrm{B} / \mathrm{Hi}$ compound cue, is similarly interpreted. Thus, in both instances, the brightness component of the compound cue had little initial relevance for the striate rat. We suggest that that is exactly what one would expect if visual decortication reduced the functional importance of the visual system.

In the final experiment of this research, we duplicated the second procedure but preoperatively trained the animals to criterion with only the brightness cues.
The results, given in Figure 11, generally replicate what we found with the lesion-first animals. There are, however, some important qualifications. These are related to the spared memories of the preoperatively learned brightness discrimination and are reflected in the postoperative recovery training with, and subsequent transfer training to, the haptic cues. In both cases, the animals do not perform as well as the lesion-first rats of the second experiment. Our explanation for this is that the spared memories of the preoperative behavior were able to influence post-
Brightness Relevant

Haptic Relevant

Brightness Relevant

Haptic Irrelevant
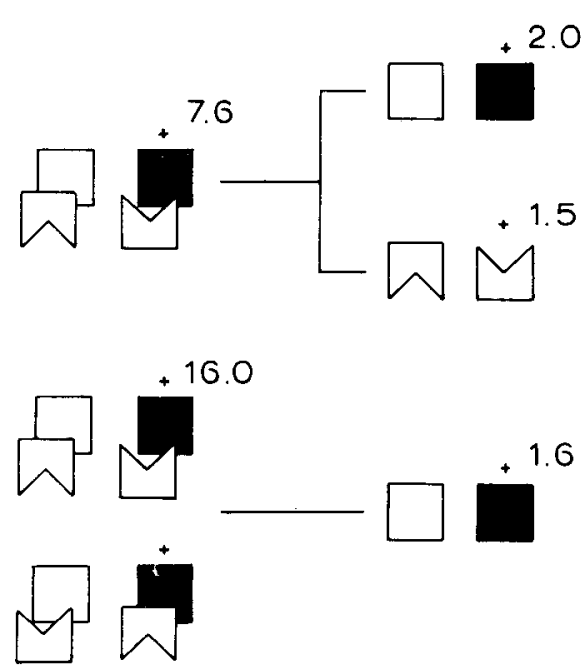

Figure 9. Diagram of the training conditions and mean errors to criterion during compound-cue training and transfer training for normal rats. See text for details. 
Compound Cue Transfer
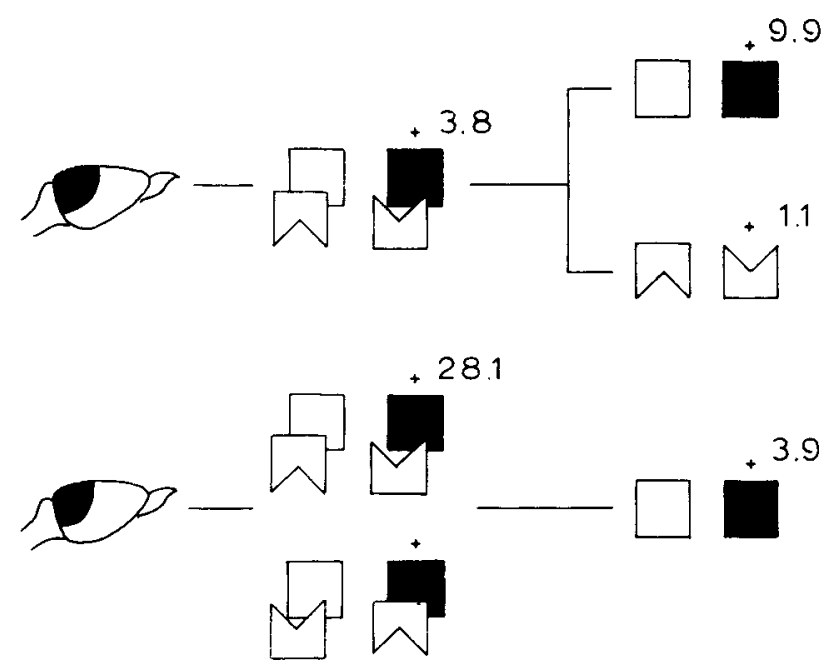

Figure 10. Similar to Figure 9, except that all animals sustained visual decortication prior to any training.

operative recovery even though the visual decorticate rat prefers to utilize haptic cues. We believe that this is a somewhat important result, because it suggests that spared memories may exert some influence on postoperative behavior even when one might predict that they should not. At least they should not if neocortical injury changes spared memories and makes them specific to the conditions under which they were established.
At this point, we felt that visual neocortical insult did not change visual memories. We also felt that we knew why spared visual memories were not easily retrieved. They were not easily retrieved because the visually decorticated rat prefers to utilize nonvisual neural systems. Yet, even given this compensatory preference for nonlesioned neural systems, spared visual memories were still nonetheless able to influence postoperative behavior, as illustrated by the last ex-

\section{Compound Cue Transfer}

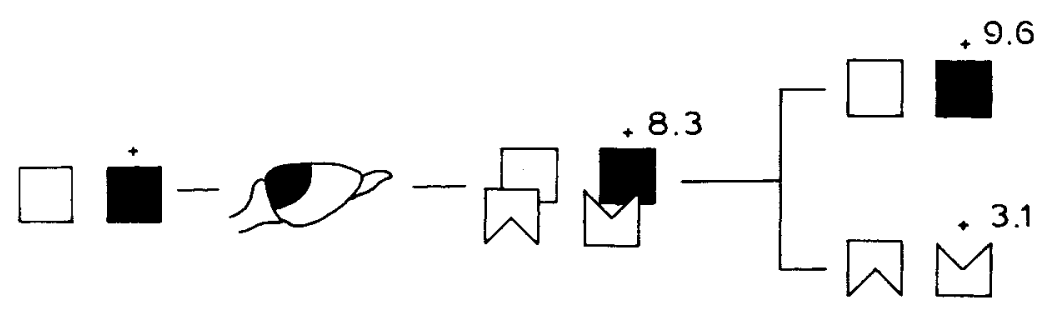

13.8

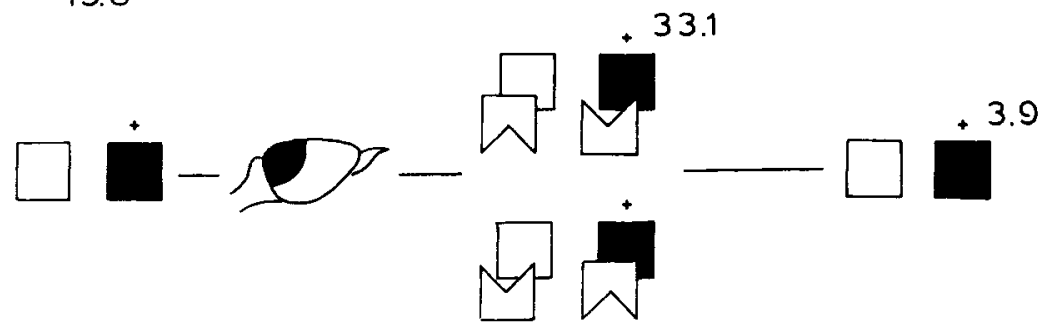

Figure 11. Similar to Figures 9 and 10, except that all animals were preoperatively required to master the brightness discrimination before being lesioned and subsequently trained with the compound-cue discrimination. 
periment. It was this finding which intrigued us, and if I might I would like to extract an indulgence and describe one final recovery experiment concerned with changes in motivation (N. D. LeVere, Chappell, \& T. E. LeVere, in press). I wish to close with this experiment because it rather clearly makes the point that neocortical injury does not make memories difficult to retrieve because it changes their nature. Rather, memories are quite stable, and it is the nature of the memory when it is stored that determines its retrieval after brain injury.

The procedure was a variation of the Davis study (T. E. LeVere \& Davis, 1977), which found that a change in motivation will prevent spared preoperative memories from influencing postoperative behavior. However, in the present research, the animals were not only preoperatively water deprived and rewarded but also, at the same time, performed to escape footshock. During postoperative recovery, the animals were just water deprived and rewarded, or they were satiated and just trained to escape footshock. Again, half of the animals recovered the originally learned brightness habit, and the other half recovered the reversal of the originally learned brightness habit. The results are given in Figure 12, which shows that, contrary to Davis's earlier findings, there is now significant reversal impairment even though motivation is changed. Apparently there is something very different about a multiply motivated habitsomething that makes its memory more resilient than similar memories of singly motivated behaviors.

What exactly this difference might be we will leave for the experts to puzzle over. However, we would like to suggest that its effect is to mitigate lesioned induced imbalances between functional neural sys-

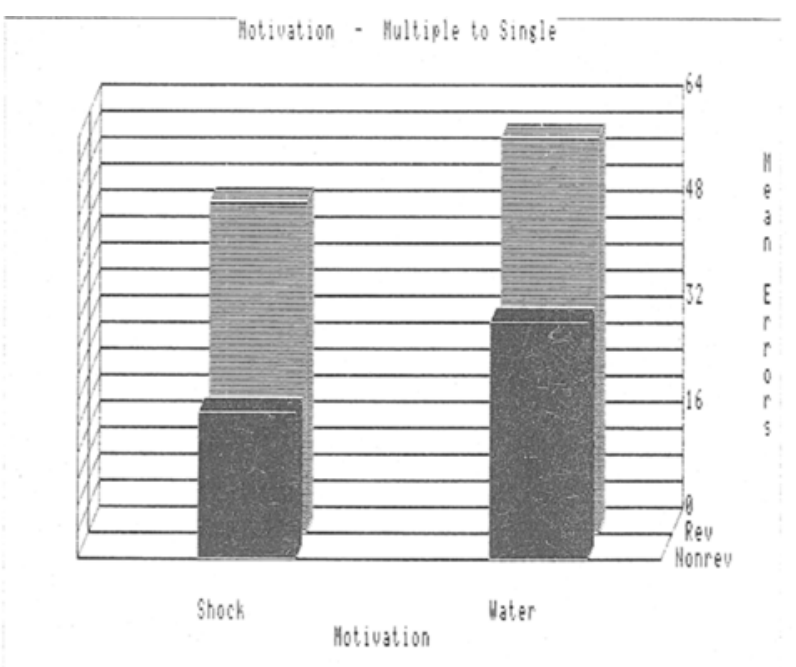

Figure 12. Postoperative nonreversal (front bars) and reversal (rear bars) errors to criterion when the preoperative brightness discrimination was learned for concurrent water/shock motivation but postoperative training was for just shock (left pair) or just water (right pair) motivation. tems. The point I would like to reemphasize is that neocortical injury does nothing to the memory itself but, rather, modulates the individual's utilization of memory. The expression, retrieval if you prefer, of a particular memory is a question of whether the memory is able to compete with the dominance of other noninjured functional systems. If it is a memory of a multiply motivated habit, or if competitive learning with dominant postoperative neural systems is retarded by drugs, then there is a greater likelihood that the memory will be expressed. But, whatever the case, the memory, when established, is established, and we suggest that there is little at the level of neocortex that will change this or the nature of the memory.

\section{REFERENCES}

Braun, J. J., Meyer, P. M., \& Meyer, D. R. (1966). Sparing of a brightness habit in rats following visual decortication. Journal of Comparative and Physiological Psychology, 61, 79-82.

Davis, N. D., \& LeVERE, T. E. (1979). Recovery of function after brain damage: Different processes and the facilitation of one. Physiological Psychology, 7, 233-240.

DAvis, N. D., \& LEVERE, T. E. (1982). Recovery of function after brain damage: The question of individual behaviors or functionality. Experimental Neurology, 75, 68-78.

Lashley, K. S. (1935). The mechanism of vision. XII. Nervous structures concerned in the acquisition and retention of habits based on reactions to light. Comparative Psychology Monographs, 11, 43-79.

LeVere, N. D., Chappell, E. T., \& LeVere, T. E. (in press). Recovery of function after brain damage: On deposits to the memory bank. Physiological Psychology.

LEVERE, T. E., \& DAvis, N. D. (1977). Recovery of function after brain damage: The motivational specificity of spared neural traces. Experimental Neurology, 57, 883-899.

LeVere, T. E., Davis, N. D., \& Gonder, L. (1979). Recovery of function after brain damage: Toward understanding the deficit. Physiological Psychology, 7, 317-326.

LEVERE, T. E., \& LEVERE, N. D. (1982). Recovery of function after brain damage: Support for the compensation theory of the behavioral deficit. Physiological Psychology, 10, 165-174.

LEVERE, T. E., \& MorLock, J. W. (1973). The nature of visual recovery following posterior decortication in the hooded rat. Journal of Comparative and Physiological Psychology, 83, 62-67.

LEVERE, T. E., \& Morlock, J. W. (1974). The influence of preoperative learning on the recovery of a successive brightness discrimination following posterior neodecortication in the hooded rat. Bulletin of the Psychonomic Society, 4, 507-509.

LuRIA, A. R. (1980). Higher cortical functions in man (2nd ed., B. Haigh, Trans.). New York: Basic Books. (Original work published 1962).

Mackintosh, N. J., McGonigle, B., Holgate, V., \& VANDERVER, V. (1968). Factors underlying improvement in serial reversal learning. Canadian Journal of Psychology, 22, 85-95.

Meyer, D. R. (1972). Access to engrams. American Psychologist, 27, 124-133.

OsGood, C. E. (1949). The similarity paradox in human learning: A resolution. Psychological Review, 56, 132-143.

Sprague, J. M. (1966). Interaction of cortex and superior colliculus in mediation of visually guided behavior in the cat. Science, 153, 1544-1547.

(Manuscript accepted for publication June 14, 1984.) 